\title{
Editorial: Current advances and challenges in understanding plant desiccation tolerance
}

\author{
John P. Moore ${ }^{1 *}$ and Jill M. Farrant ${ }^{2 *}$ \\ ${ }^{1}$ Department of Viticulture and Oenology, Faculty of AgriSciences, Institute for Wine Biotechnology, Stellenbosch University, \\ Stellenbosch, South Africa, ${ }^{2}$ Department of Molecular and Cell Biology, University of Cape Town, Cape Town, South Africa
}

Keywords: resurrection plants, plant desiccation tolerance, seed desiccation tolerance, plant genome evolution, plant evolution

\section{Understanding Plant Desiccation Tolerance - A Global Perspective}

One of the most exciting and gratifying privileges of having edited this research topic on plant desiccation tolerance is that we received papers and reviews on resurrection plant species (particularly angiosperms) covering five continents, almost six, although unfortunately we did not quite get there. We were certainly incredibly fortunate for the kind responses of colleagues in Africa (Berjak and Pammenter, 2013, 2014), South America (Suguiyama et al., 2014), Asia (Mitra et al., 2013), Europe (Benina et al., 2013; Rakic et al., 2014), and Australia (Griffiths et al., 2014); for providing us with papers dealing with their own (favorite) particular resurrection plant species and

OPEN ACCESS

Edited and reviewed by: Steven Carl Huber,

United States Department of Agriculture - Agricultural Research Service, USA

*Correspondence: John P. Moore

moorejp@sun.ac.za; Jill M. Farrant

jill.farrant@uct.ac.za

Specialty section:

This article was submitted to Plant Physiology,

a section of the journal

Frontiers in Plant Science

Received: 02 September 2015 Accepted: 07 September 2015 Published: 29 September 2015

Citation: Moore JP and Farrant JM (2015) Editorial: Current advances and challenges in understanding plant

desiccation tolerance.

Front. Plant Sci. 6:768.

doi: 10.3389/fpls.2015.00768 the recent discoveries that they have made. It is with this in mind that we are moving toward a more global understanding of resurrection plants, and angiosperm species in particular, although often referred to as being particularly rich in diversity in southern Africa (Moore et al., 2009). We have noted that more and more studies are being made of resurrection species around the globe, as species are being uncovered in China such as Boea hygrometrica (this research topic, Mitra et al., 2013) and Paraboea rufescens (Huang et al., 2012) both in the Gesneriaceae and in South America Also in Brazil specifically, with Barbacenia purpurea (this research topic, Suguiyama et al., 2014) in the Velloziaeace. It is with this in mind that we are realizing more and more that plant desiccation tolerance in angiosperms is far less uncommon than previously suspected, and certainly has re-evolved as an adaptive feature on all continents (except for the South Pole, but this may well be provisional). We start off our quest for understanding plant desiccation tolerance with the green algae; here we are grateful for the first comprehensive review on this under-studied area, with a contribution from Holzinger and Karstens (2013). It is clear that algal cells were obviously the first "plants" to experience desiccation during land plant evolution. Far from following a simple single strategy, Holzinger and Karstens (2013) show that a variety of strategies appear to be employed to mitigate desiccation in both the Streptophyta and Chlorophyta lineages. We were hoping to include lichens and bryophytes (mosses), but these have been adequately covered in Moore et al. (2009). Our shift into the angiosperms, starts with an unlikely species, Arabidopsis thaliana (Djafi et al., 2013), however much is inferred, developed, tested using the Arabidopsis genetic model. In this case, an important area of angiosperm desiccation tolerance involves signaling (Moore et al., 2009), and Djafi et al. (2013) in their study focus on the phospoholipase $\mathrm{C}$ genes/proteins that are known to be triggered in response to dehydration. Djafi et al. (2013) have performed a thorough transcriptome study in A. thaliana using the presence of inhibitors that identified a set of DREB2 (Dehyration Response Element Binding) regulatory genes involved in dehydration stress responses. Moving into resurrection plants we were fortunate to have received such a comprehensive review by Dinakar and Bartels (2013) of the various-omics 
studies (i.e., transcriptome, proteome, and metabolome) that has been performed on a variety of resurrection plants. Dinakar and Bartels (2013) have done an admirable effort to cover the variety of species evaluated at the molecular level; including Craterostigma plantagineum, Haberlea rhodopensis, Xerophyta viscosa, B. hygrometrica, Sporobolus stapfianus, and Selaginella stapfianus. A more specific review of the emerging model resurrection plant species $B$. hygrometrica from China was provided by Mitra et al. (2013). The authors conclude with a number of molecular factors that play a role in desiccation tolerance of $B$. hygrometrica before discussing future perspectives. We received two papers on resurrection plant species from the Balkan peninsula of Europe one on the genus Ramonda (Rakic et al., 2014) and the other on the species $H$. rhodopensis (Benina et al., 2013). The study by Rakic et al. (2014) focusses on the genus Ramonda and discusses aspects of their physiology, cytogenetics and biogeography. Benina et al. (2013) performed a comparative metabolic profiling study on $H$. rhodopensis, Thellungiella halophyla, and A. thaliana under cold stress showing that sugars, polyols, and organic acids accumulate as the main metabolites in the resurrection plant. Suguiyama et al. (2014) show that summer plants of $B$. purpurea are primed for desiccation, while winter plants show a two time-dependent response, involving metabolite accumulation, particularly the production of caffeoyl-quinic acids.

\section{The Evolution of Angiosperm Resurrection Plants - The Secret in the Seeds?}

Farrant and Moore (2011) proposed that angiosperm resurrection plants acquired tolerance by re-activating their innate seed specific genetic elements in their vegetative tissues.

\section{References}

Benina, M., Obata, T., Mehterov, N., Ivan, I., Petrov, V., Toneva, V., et al. (2013). Comparative metabolic profiling of Haberlea rhodopensis, Thellungiella halophyla, and Arabidopsis thaliana exposed to low temperature. Front. Plant Sci. 4:449. doi: 10.3389/fpls.2013.00499

Berjak, P., and Pammenter, N. W. (2013). Implications of the lack of desiccation tolerance in recalcitrant seeds. Front. Plant Sci. 4:478. doi: 10.3389/fpls.2013.00478

Berjak, P., and Pammenter, N. W. (2014). Corrigendum: implications of the lack of desiccation tolerance in recalcitrant seeds. Front. Plant Sci. 5:123. doi: 10.3389/fpls.2014.00123

Bewley, J. D., Bradford, K. J., Hilhorst, H. W. M., and Nonogaki, H. (2013). Seeds Physiology of Development, Germination and Dormancy, 3rd Edn. Heidelberg: Springer.

Dinakar, C., and Bartels, D. (2013). Desiccation tolerance in resurrection plants: new insights from transcriptome, proteome, and metabolome analysis. Front. Plant Sci. 4:482. doi: 10.3389/fpls.2013.00482

Djafi, N., Vergnolle, C., Cantrel, C., Wietrzyñski, W., Delage, E., Cochet, F., et al. (2013). The Arabidopsis DREB2 genetic pathway is constitutively repressed by basal phosphoinositide-dependentphospholipase C coupled to diacylglycerol kinase. Front. Plant Sci. 4:307. doi: 10.3389/fpls.2013. 00307
Again we were fortunate to receive an excellent review on the lack of desiccation tolerance in recalcitrant (vs. orthodox) seeds by Berjak and Pammenter (2013). We were delighted to receive a novel study on the "seed desiccome" of Medicago truncatula, a seed model system, by Terrasson et al. (2013). This work identified 48 transcription factors involved in flowering transition, which the authors suggest were involved in co-opting the existing pathways during the evolution of desiccation tolerance in angiosperms. Given that programmed cell death is involved in seed physiology (Bewley et al., 2013) and processes such as senescence, it was therefore most satisfying to receive a review by Griffiths et al. (2014) on the role of senescence in resurrection plants. This topic has not been investigated in any depth, the authors draw on their own studies on $S$. stapfianus, to buttress their hypotheses on how senescence may be differentially activated and suppressed in resurrection plant evolution. The first sequenced genome of a resurrection plant, the Chinese B. hygrometrica (reviewed here by Mitra et al., 2013) was published this year by Xiao et al. (2015). This will pave the way for more functional genomic studies to elucidate the mechanisms underpinning desiccation tolerance in this as well as other species. It would seem we are only "at the end of the beginning" in our quest to understand the remarkable biological secrets of these fascinating plants.

\section{Acknowledgments}

Finally, we are indebted and grateful to all of the authors, reviewers and the Frontiers editorial staff for the generous support of this research topic project. We would like to dedicate this special issue to the memory of the late Professor Patricia Berjak, an internationally acclaimed scientist, mentor, colleague and friend.
Farrant, J. M., and Moore, J. P. (2011). Programming desiccation-tolerance: from plants to seeds to resurrection plants. Curr. Opin. Plant Biol. 14, 1-6. doi: 10.1016/j.pbi.2011.03.018

Griffiths, C. A., Gaff, D. A., and Neale, A. D. (2014). Drying without senescence in resurrection plants. Front. Plant Sci. 5:36. doi: 10.3389/fpls.2014.00036

Huang, W., Yang, S. J., Zhang, S. B., Zhang, J. L., and Cao, K. F. (2012). Cyclic electron flow plays an important role in photoprotection for the resurrection plant Paraboea rufescens under drought stress. Planta 235, 819-828. doi: 10.1007/s00425-011-1544-3

Holzinger, A., and Karstens, U. (2013). Desiccation stress and tolerance in green algae: consequences for ultrastructure, physiological, and molecular mechanisms. Front. Plant Sci. 4:327. doi: 10.3389/fpls.2013.0327

Mitra, J., Xu, G., Wang, B., Li, M., and Deng, X. (2013). Understanding desiccation tolerance using the resurrection plant Boea hygrometrica as a model system. Front. Plant Sci. 4:446. doi: 10.3389/fpls.2013.00446

Moore, J. P., Le, N. T., Brandt, W. F., Driouich, A. D., and Farrant, J. M. (2009). Towards a systems-based understanding of plant desiccation tolerance. Trends Plant Sci. 14, 110-117. doi: 10.1016/j.tplants.2008.11.007

Rakic, T., Lazarevic, M., Jovanovic, Z. S., Radovic, S., Siljak-Yakovlev, S., Stevanovic, B., et al. (2014). Resurrection plants of the genus Ramonda: prospective survival strategies - unlock further capacity of adaptation, or embark on the path of evolution? Front. Plant Sci. 4:550. doi: $10.3389 /$ fpls.2013.00550 
Suguiyama, V. F., Silva, E. A., Meirelles, S. T., Centeno, D. C., and Braga, M. R. (2014). Leaf metabolite profile of the Brazilian resurrection plant Barbacenia purpurea Hook. (Velloziaceae) shows two time-dependent responses during desiccation and recovering. Front. Plant Sci. 5:96. doi: 10.3389/fpls.2014.00096 Terrasson, E., Buitink, J., Righetti, K., Ly Vu, B., Pelletier, S., Zinsmeister, J., et al. (2013). An emerging picture of the seed desiccome: confirmed regulators and newcomers identified using transcriptome comparison. Front. Plant Sci. 4:497. doi: 10.3389/fpls.2013.00497

Xiao, L., Yang, G., Zhang, L., Yang, X., Zhao, S., Ji, Z., et al. (2015). The resurrection genome of Boea hygrometrica: a blueprint for survival of dehydration. Proc. Natl. Acad. Sci. U.S.A. 112, 5833-5837. doi: 10.1073/pnas.1505811112
Conflict of Interest Statement: The authors declare that the research was conducted in the absence of any commercial or financial relationships that could be construed as a potential conflict of interest.

Copyright $\odot 2015$ Moore and Farrant. This is an open-access article distributed under the terms of the Creative Commons Attribution License (CC BY). The use, distribution or reproduction in other forums is permitted, provided the original author(s) or licensor are credited and that the original publication in this journal is cited, in accordance with accepted academic practice. No use, distribution or reproduction is permitted which does not comply with these terms. 